\title{
INTEGRATED 3D SURVEY AND DIAGNOSTIC ANALYSIS FOR THE BUILDING ENGINEERING: THE FORMER KINDERGARTEN SAN FILIPPO NERI IN DALMINE
}

\author{
Pietro Azzola ${ }^{1}$, Alessio Cardaci $^{1}$, Antonella Versaci $^{2}$ \\ ${ }^{1}$ Department of Engineering and S.A., University of Bergamo, Bergamo, Italy \\ pietro.azzola@unibg.it - alessio.cardaci@unibg.it \\ ${ }^{2}$ Faculty of Engineering and Architecture, University of Enna "Kore", Enna, Italy \\ antonella.versaci@unikore.it
}

Commission II

KEY WORDS: Dalmine, Former kindergarten San Filippo Neri, Integrated Architectural Survey, Conservation, Adaptive Reuse

\begin{abstract}
:
The paper aims to emphasise the positive contribution that the 3D laser scanning and digital photogrammetry survey, integrated with diagnostic analysis techniques, can make in the field of construction engineering. The case study of the former kindergarten San Filippo Neri in Dalmine intends to contribute to the development of methodologies and operational tools related to the knowledge and conservation of modern and contemporary heritage. After archival research aimed at retracing the building's technicalconstructive evolution, the study was extended out through the metric and morphological survey of both its external walls and internal spaces, paying special attention to the analysis of the deformations of the large horizontal surfaces, such as floors and ceilings. Diagnostic investigations - thermographic and microclimatic - have completed the survey campaign, so allowed to read both the envelope and the substance of the building, and to identify the critical issues. This work adopts and shows the correct glide slope to succeed in an adaptive reuse project in which the design stage can result solely from the in-depth study of the building.
\end{abstract}

\section{INTRODUCTION}

The survey aimed to a built heritage project, valued in its widest sense as an instrument of knowledge for conservation, is a 'project in the project'. Its intention is the interpretation and discernment of the construction to provide every possible information to operate in a punctual and correct manner on its materials, effects and the causal agents that get the decay phenomena.

It is a cognitive investigation, of geometrical/functional and diagnostic nature, which is an integral part of the process of safeguarding and an indispensable tool for verifying the effectiveness of the envisaged solutions, as well as to orient the direction of new and/or further action proposals.

Actually, the link between knowledge and design is inseparable, both to recognise the physical and material coherence of the architectural object, and to understand its components, stratifications and signs of the time that have transformed it into 'a unique and irreproducible monument' (Cardaci and Versaci, 2018).

Thus, the building intervention starts with the representation, at different scales, of the existing model relating to a precise time, and responding, case by case, with its contemporary needs and demands. In fact, "there is no more subjective and contextual practice than an architectural survey, strictly linked to the purposes and consequently to the ways and times of its elaboration. Each survey is a singular and certainly unrepeatable document (...) therefore, no survey of a monument or building can be considered definitive" (Dezzi Bardeschi, 1990).

Indeed, the understanding is not the result of a heterogeneous set of information, but derives from a global analysis of the data obtained from the enquiry carried out. A coordinated work that allows correlating, within a unitary and conscious vision, every cognitive activity to respectfully investigate, the critical aspects of the architectural structure (Campanella, 2017).

This entails the specific knowledge of the detector/restorer about both modern detection techniques and diagnostic investigation, to discern their use, to interpret their limits and exploit their potentialities. It is clear, therefore, that the survey for the conservation project is quite different from a simple documentation of the architectural object and that it requires greater awareness, a preparatory planning of the activities and the constant verification of the operations planned and performed.

Although the continuous advancement of technology offers new tools, only the competence and awareness of the designer generates a good project on the built. Consequently, it is essential that he deeply knows the edifice on which it works and its context, learns its unique and unrepeatable history and, as a doctor does with his patient, undertakes the right analysis to assess its state of health (Bianchi et al, 2016).

The study on the former kindergarten San Filippo Neri intends to show and confirm the opportunities that 3D laser scanning and digital photogrammetric surveying techniques can offer in the construction sector, analysing the scientific, technical and technological aspects, illustrating the operative procedures, shedding light on their most interesting features. The goal is to underline the absolute importance of the phase of knowledge, which should not be an end in itself, but a necessary condition for the success of a project.

\section{THE SAN FILIPPO NERI KINDERGARTEN}

The city of Dalmine is a new town built in the first half of the $20^{\text {th }}$ century in a location just outside Bergamo, on the way to Milan. The urban design was entrusted to the architect Giovanni 
Greppi who was asked to create an ideal village: a 'selfsufficient microcosm' envisaged to meet the needs of workers and their families, both with residences and public facilities such as social, cultural and welfare buildings (Lussana, 2003).

The kindergarten was among the first structures built at the end of the 1920s (figure 1). Its first design, set on a rigid biaxial symmetry, was centred on a bright entrance (linking the treelined avenue and the garden), two large classrooms, where the infants divided by age groups carried out their activities, and some other service rooms.

The simple hall portal was conceived with the same figuration, both in the east front and the west front. It was characterized by a tripartite system with non-fluted columns in Ionic style and surmounted by a 'pagoda' tympanum.

The urban growth of the city after World War II and the need to have new spaces was the determining factor of a first transformation of the school in 1955. An extension was made in the same style with the repetition of the architectural elements and the addition of two new classrooms and a portico on the back side. Later, between 1967 and 1970, a new transformation with the construction of another brickwork in reinforced concrete allowed the creation of three new classrooms, some dormitory and other toilets (figure 2).

The kindergarten closed in 2008 following the construction of a larger and more modern structure. The abandoned building had a major decline in quality due to lack of maintenance (Cardaci et al, 2018).

The Municipality of Dalmine has shown, in recent years, the intention to readjust the existing space to accommodate the new administration offices; hence, the need for a knowledge project in order to orient the future adaptive reuse project.

\section{THE SURVEY AND THE DIAGNOSTIC INVESTIGATION}

A project on an existing structure needs extreme caution and great sensitivity, in addition to specific technical skills. The direct and instrumental observation of the architecture is, in fact, an indispensable condition for grasping, in a more or less evident way, its history and evolution. The constructive anomalies, the irregularities, the degeneration and decay manifestations are all signals that the artefact transmits to an experienced observer.

The study conducted on the former kindergarten was developed starting from a careful historical and archival research followed by in-situ relevant activities (direct and indirect with 3D Laser Scanning and Digital Photogrammetry technology) and thermographic and thermo-hygrometric non-invasive diagnostic analysis.

The utilisation of both modern equipment and recent software, able to interface with each other within shared platforms, allowed to manage in a single virtual model all the metric, material and thermal information on the building.

This has permitted to pinpoint the most critical areas and to indicate the zones of alteration or physical stress, by surrounding them in extension and providing - in a multicolour display - information on the severity of the phenomena.

\subsection{The 3D laser scanning survey}

The 3D laser scanning performed provided a high-reliability geometric framework in order to overlap photogrammetric and thermographic models. The metric data obtained (without the overlap of the colour data) have been geo-referenced in a single global reference system thanks to the knowledge of the $3 \mathrm{D}$ coordinates of some points (support points) detected by

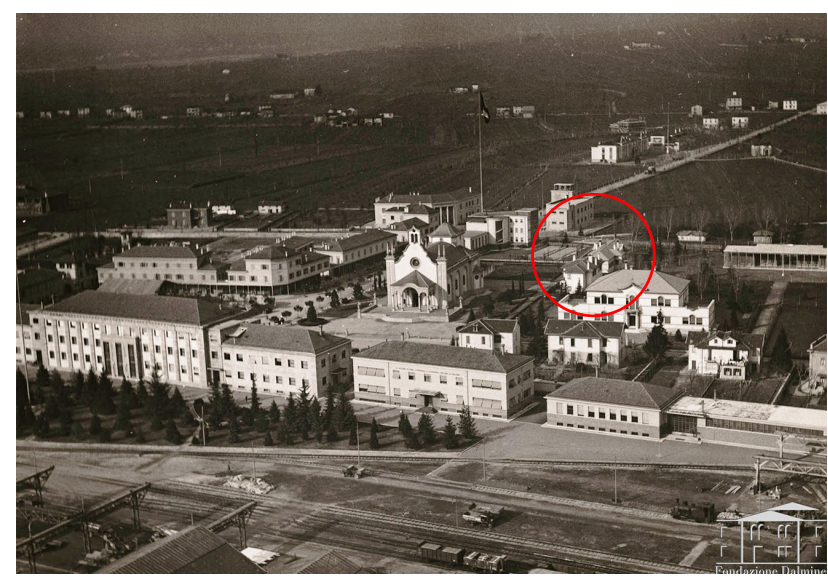

Figure 1. The city of Dalmine in the first half of the $20^{\text {th }}$ century: in the box the kindergarten San Filippo Neri.
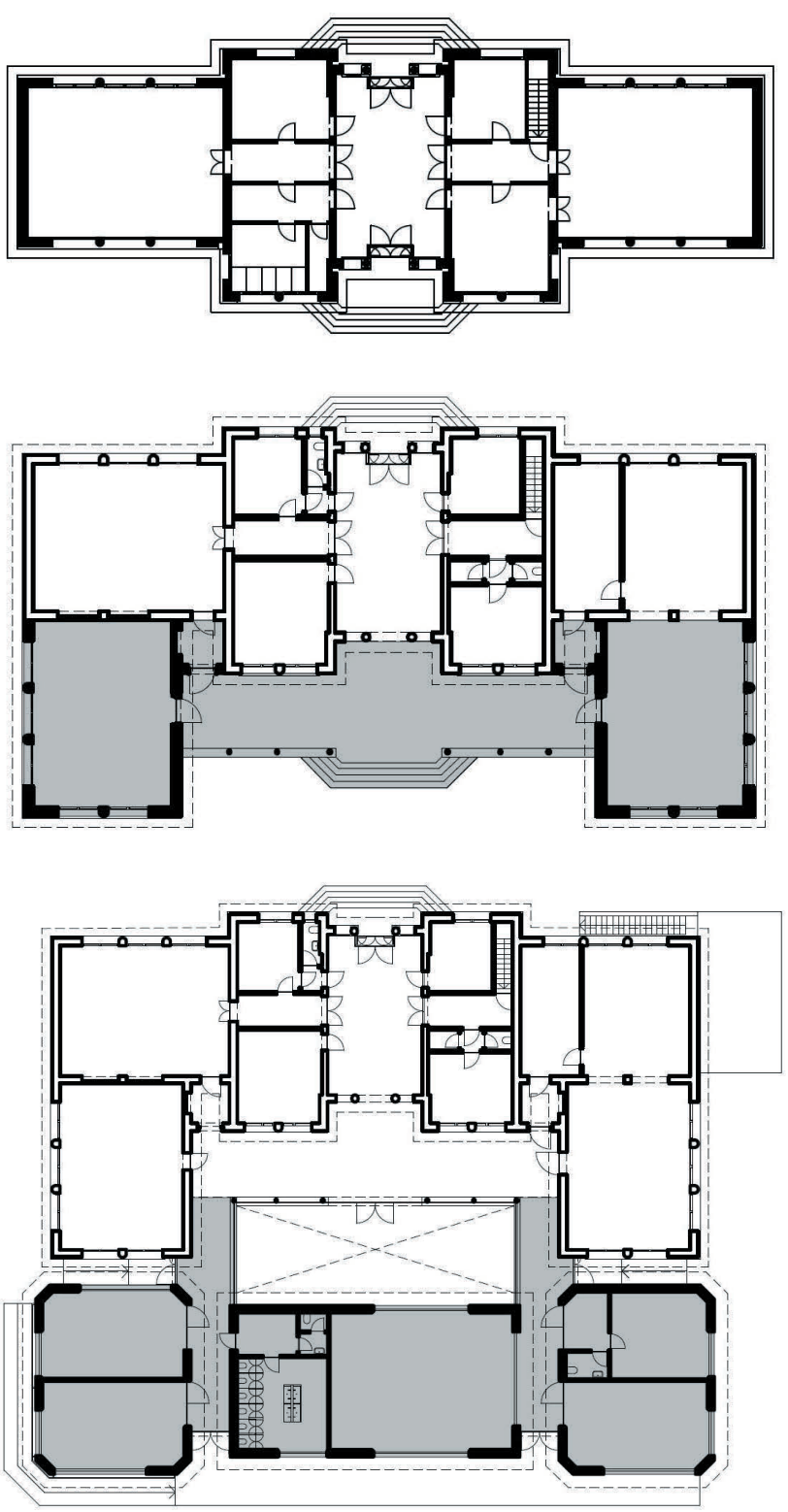

Figure 2. The kindergarten San Filippo Neri: the plan-view of the building as it was in the 1930s, in the 1960s and today. 
topographic methods. The construction of the complete model required about 50 scans for the building and about 25 in the surrounding area. In special, the entire perimeter and all its internal rooms on the ground floor and basement were acquired while for security reasons, it was not possible to detect the roof with the desired resolution.

The processing was carried out with the software ${ }^{\circledR} F A R O$ SCENE 7.1; the midpoint error of $2.6 \mathrm{~mm}$ with a minimum overlap of $24.1 \%$ was the sign of the high precision of the model. The maximum error value of $14.2 \mathrm{~mm}$ point provided by the program was less relevant, negatively affected by the displacement errors determined, for example, by the vegetation moved by the wind.

The final cloud, of over 50 million points, has been investigated by navigating it also in "Virtual Reality" mode with a stereoscopic viewer; the planes and clipping boxes were set in order to intercept the most interesting construction elements (figure 3, 4).

The accuracy of the model allowed to verify geometric irregularities such as topping deflections. The stability check was carried out using the software C3DFlow Zephyr, intersecting the model with horizontal cutting planes with a constant pitch of $10 \mathrm{~mm}$; a graph was therefore drawn with the trend of the isolines at a constant altitude, in order to display the altimetry trend of the floors intrados (figures 5).

The ceiling of the building has been placed at two different heights. The oldest part is the highest and is positioned at a height of approximately $+4.36 \mathrm{~m}$ from the middling point of the floor, while the most recent part is the lowest and it is located at a peak of $+3.57 \mathrm{~m}$ from the middling point of the base.

Geometric analyses have highlighted serious problems. In particular, there are high gradients of lowering in the oldest part of the building; here, local lowering reaches high and disturbing values ( $>$ than $17 \mathrm{~cm}$ on average lights of $575 \mathrm{~cm}$ ). The output of the illustrated procedure is a composition of *.dxf files which make up the exact scale orthophotos of the elements of interest.

\subsection{The photogrammetric survey}

The photogrammetric survey, integrated with the 3D laser scanner acquisitions, completed the global model with the photochromic data. In fact, radiometric and colour data are indispensable components in the correct analysis of surface alterations.

A correct procedure starts with a rigorous calibration of the lens used during the photo taking, in order to limit errors with a precorrection of the geometric distortions of the images. A double method calculated the internal parameters of the cameras in order to compare the final values. A first calibration was performed with the 'metric display' of the software ${ }^{\circledR} 3 \mathrm{DFlow}$ Zephyr; a second calibration was done with a dedicated (BMATLAB application software. The coincidence in the results confirmed the goodness of the values employed.

The shots were taken by a Canon Eos5 Mark III full-frame camera and a $24 \mathrm{~mm}$ high-brightness $\mathrm{f} / 14$ lens. The images were acquired with low ISO values in aperture priority mode so the depth of field and the sharp area were maximized. They were taken with the device mounted on a tripod and carefully programming the position of each gripping station in order to guarantee uniform coverage of the elevations and ceilings.

The photo survey was carried out with great precaution in order to avoid shaded areas and to obtain an overlap of $70 \%$ or more and a Ground Sampling Distance (G.S.D.) - the pixel dimension on the real surface of the building - adjusted to return to $1: 50$ scale. Due to the focal length of the used lens, it was considered appropriate to fix a distance from the surfaces of less than $5.5 \mathrm{~m}$

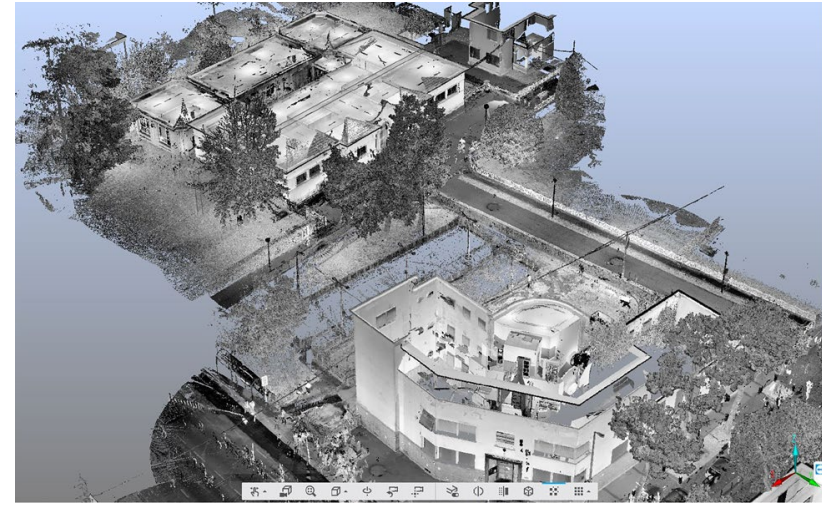

Figure 3. 3D laser scanner survey: the point clouds of the former kindergarten San Filippo Neri and its environment.
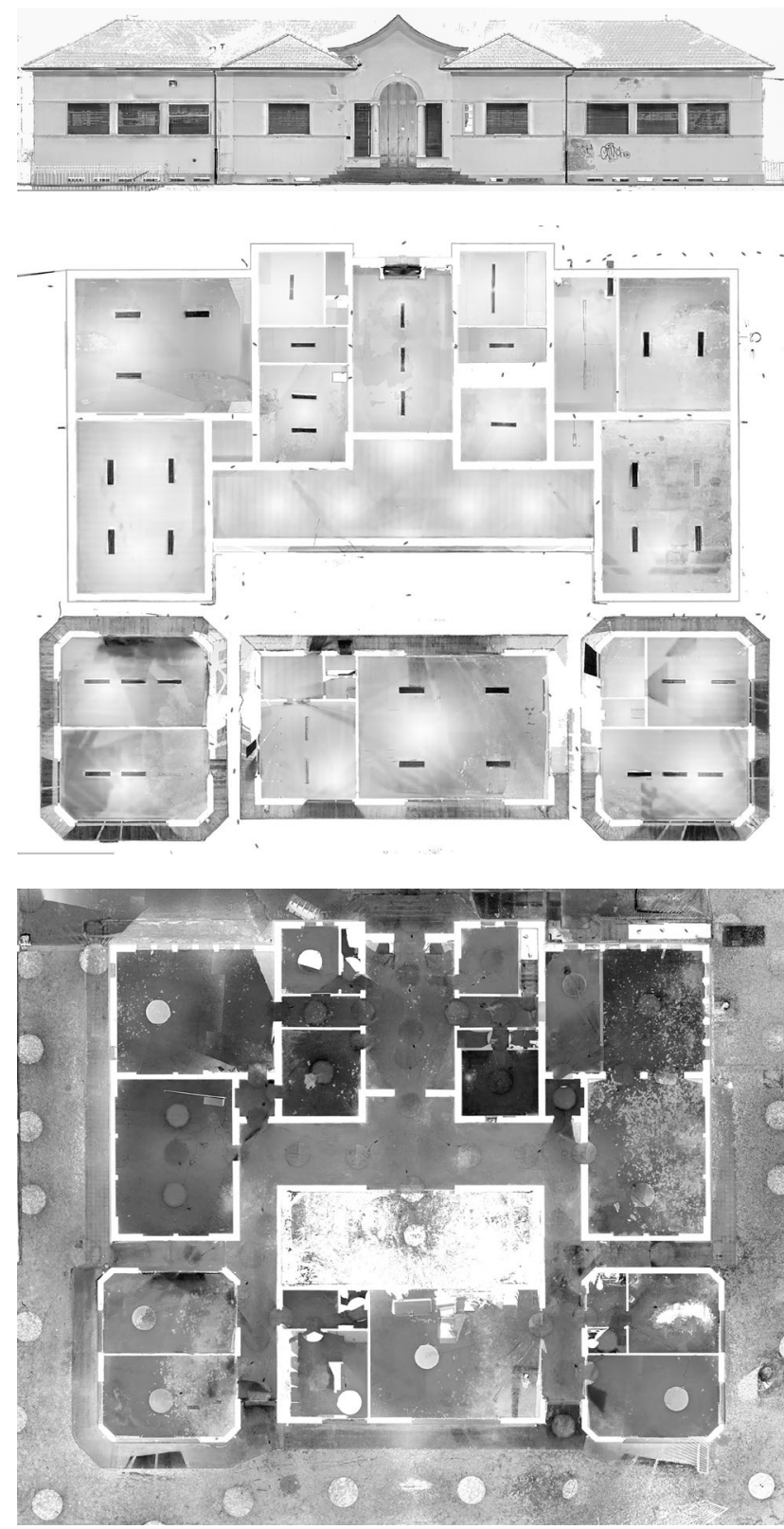

Figure 4. 3D laser scanner survey: the orthophotos of the facade, ceilings and floor plan. 


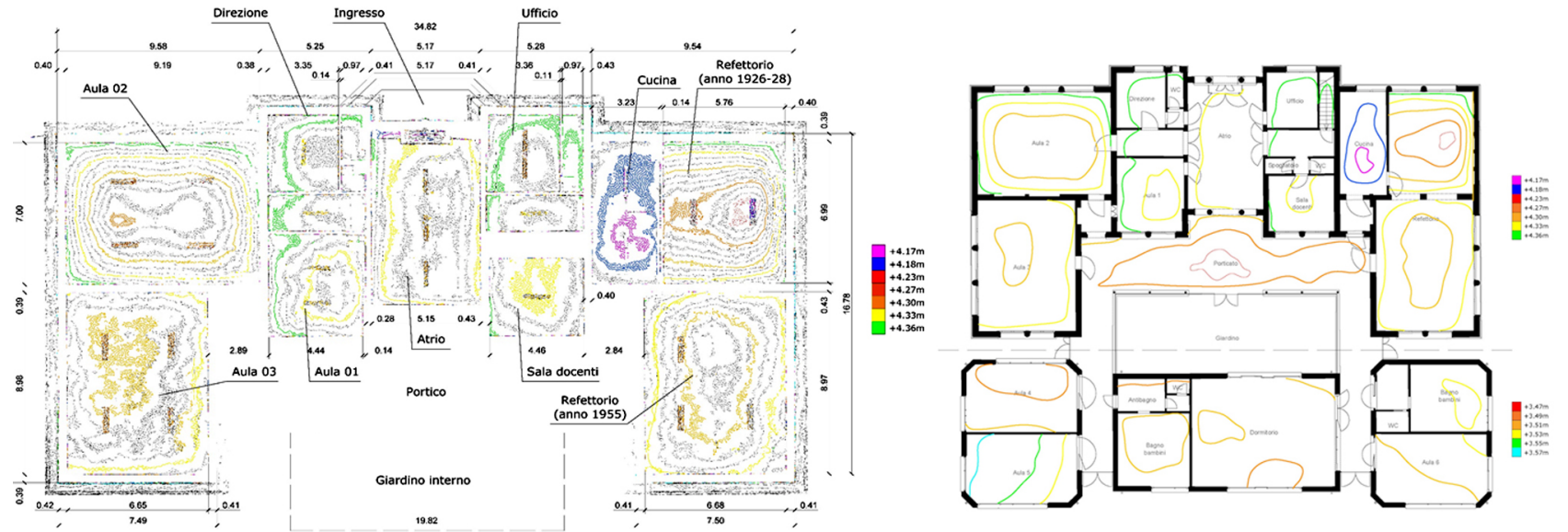

Figure 5. The analysis of the topping deflections.

to obtain a resolution of $1 \mathrm{pixel} / \mathrm{mm}^{2}$. The choice to acquire HDR images improved the sharpness and the wealth of details. Therefore, it was necessary to make multiple shots from the same position with different exposures, to compensate for the loss of particulars in the underexposed or overexposed areas of each individual picture.

With the purpose to optimize time, the automatic camera bracketing function was used: only three shots were made for every single image with a range of $1.3 \mathrm{EV}$ and HDR image processing was done with the software CAdobe Lightroom.

Moreover, in order to correct the chromatic alterations acquired with different colour temperatures, a chromatic characterization was carried out thanks to the use of a single "colour profile", previously elaborated with the system X-Rite ColorChecker $\subset$ Passport and elaborated with the software (C)Adobe Camera Raw. It was necessary to perform both the shots with the camera parallel to the surfaces, and other shaky shots at the elevation, with the optical axis rotated about 60 degrees compared to the façade, in order to have the necessary information both out-ofthe plane and related to the presence of jalousies, balconies, ledges and mouldings. In order to have metric indications directly from the individual images, before processing, in some frames appear simple measuring instruments such as stadia and rigid meters.

The realization of photogrammetric models originates from different software to compare the results; in particular, the images have been elaborated with ${ }^{\circledR}$ Agisoft PhotoScan, (®3DFlow Zephyr Aerial and ${ }^{\circledR}$ Pix4D Mapper software.

The elaborations were made by grouping the images into chunks to be processed individually; the numerous high- definition images, in fact, required a great computational commitment, especially in the reconstruction of small architectural elements rich in detail (small protruding mouldings, the capitals at the of the columns, decorative elements).

Different algorithms for different software have allowed the realization of three different models, each one suitable for different purposes: three different 'clothes' that overlapped the point cloud created by the 3D laser scanning survey, operated within the ${ }^{\circledR} 3$ DFlow Zephyr Aerial working environment (Pepe et al., 2016). The overlap between the $3 \mathrm{D}$ laser scanner model and the photogrammetric model did not take place based on known coordinates but through the recognition of homologous points; the procedure was refined through some error minimization algorithms by Iterative Closest Point procedure (figure. 6).

The 3D model allowed the production of orthographic projections of the elevations, floors and counter-floors and the graphic supports necessary for the definition of the conservation project (Rocha et al., 2018).

The drawings, produced at a scale of 1:50, have been integrated with two-dimensional photographic stitching techniques in order to complete the gaps relating to the transparent parts such the windows or other reflective metal fixtures and elements, not reconstructed through the photogrammetric process (figure. 7).

\subsection{Quantitative investigations and qualitative survey}

The only metrical and material knowledge does not complete the building comprehension; the diagnostic investigation, declined in its different meanings and operative practices, has
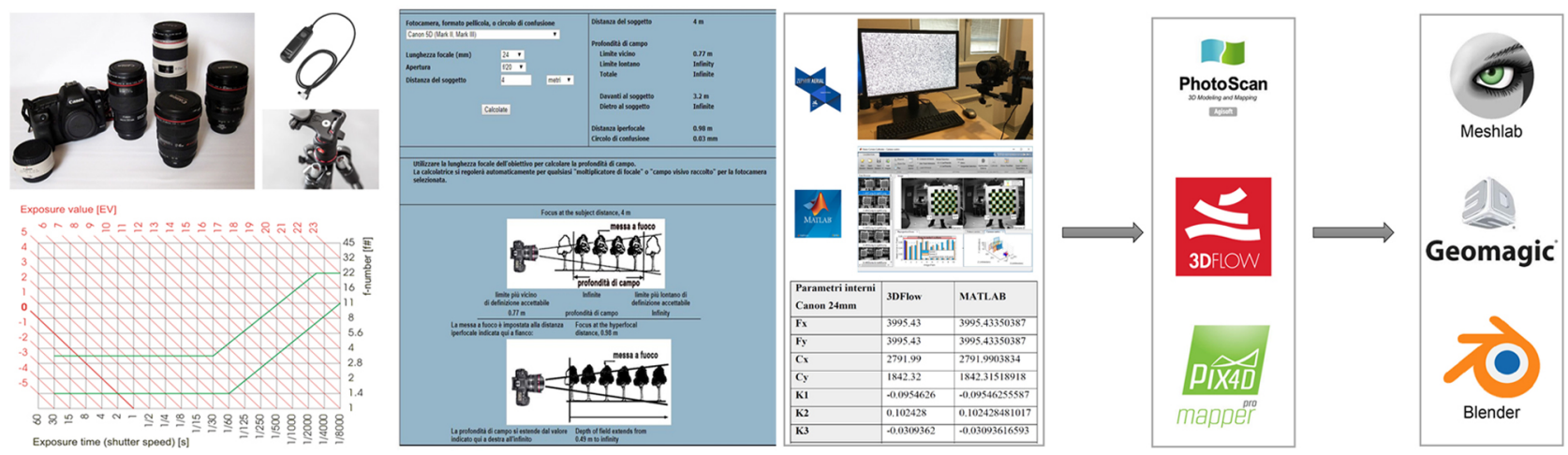

Figure 6. The workflow of photogrammetric survey: the camera calibration, the 3D Reconstruction and the 3D modelling. 

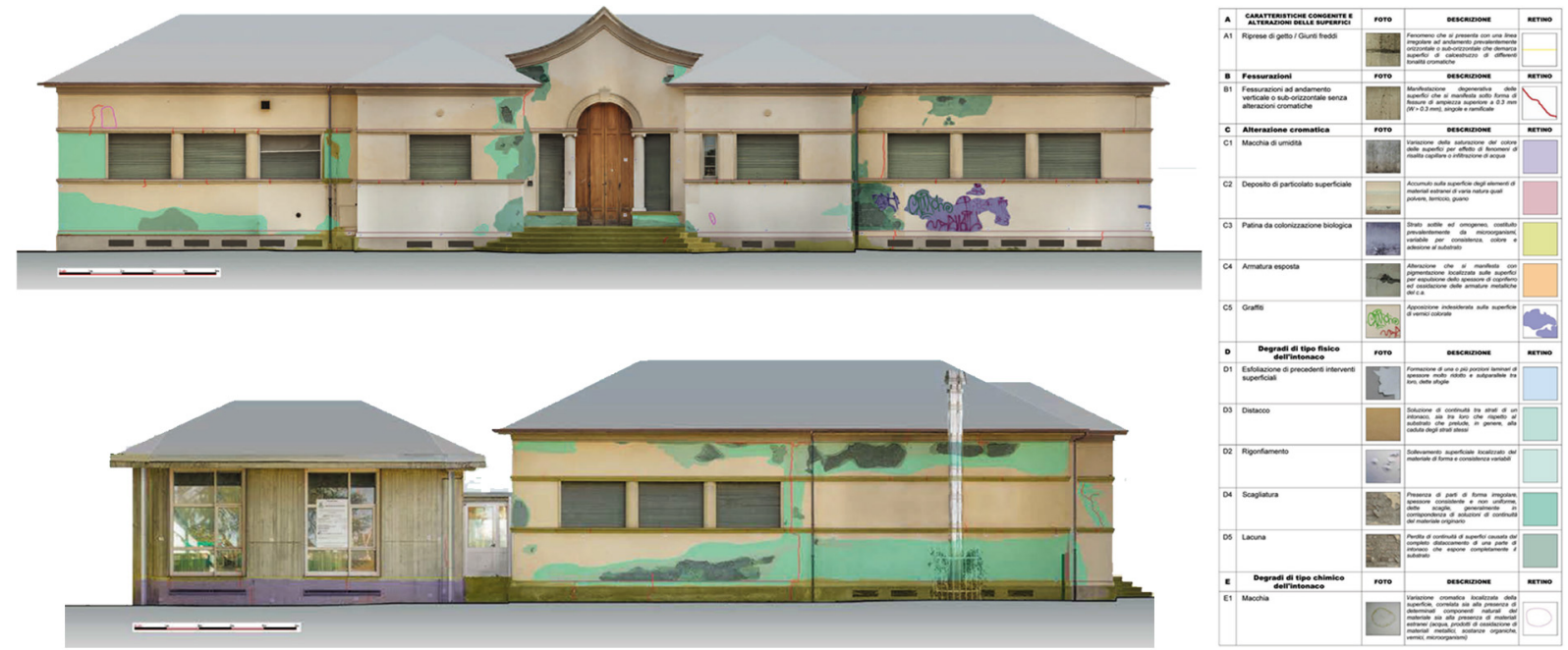

Figure 7. The identification of decay phenomena.

long been applied in the activity on the building heritage and takes an important role for the intervention phase (Bellini \& Torsello, 2005).

Passive thermographic and hygrometric investigations, which identify and quantify physical phenomena without artificial stimulation interventions, can be carried out in a simple and easy way; they provide a precise picture of both environmental values and the architectural structures' conditions.

The microclimate analysis was taken along two different days, respectively in the winter and summer seasons. To complete the study, the exposure of the various environments to the variability of the hours of the day was considered, in order to evaluate the energy contribution due to solar radiation (Sciurpi et al, 2018). A mapping of the entire building and the external environment was carried out based on a grid of 244 measuring points. The temperature and relative humidity of the air, as well as the temperature of the floor and the ceiling (assuming an emissivity value $\varepsilon=0.90$ ), were detected.

The data obtained allowed identifying the construction phases of the former kindergarten highlighting the discontinuity of the construction elements and of the materials present under the cortical layer. It permitted to understand the texture of the wall elements, to identify the buffered openings, the flues and the pipes, the structural elements (figure. 8).

The thermographic survey proved to be a valid tool for the analysis of the areas affected by humidity and thermal dispersion places; the lighter or darker colouring has returned the thermic maps (the map of thermal leaks, thermal bridges and condensation zones, structural discontinuities, and biological assaults) of the degradation phenomena (Costanzo et al., 2015; Bison et al. 2012).

The surveys led to identifying the building pathologies, both related to the structural system and materials. They were represented directly on the photorealistic projections - through semi-transparent patterns to allow an interpretation at multiple levels of the documents - and a specific lexicon was defined to synthetically describe them (Rosina, 2009).

The phenomena were identified according to the ways in which they take place. In particular, they have been subdivided among those linked mainly to congenital defects and constructive and/or design errors (especially in the recent concrete body) and which have caused the emergence of a cracks pattern due to internal stresses; and other problems which took place later as a result of attacks by atmospheric elements or deriving from the natural aging of the superficial matter (figure. 9).

\section{CONCLUSIONS}

The approach to a building belonging to a past still not sufficiently historicized but still worthy of respect as important
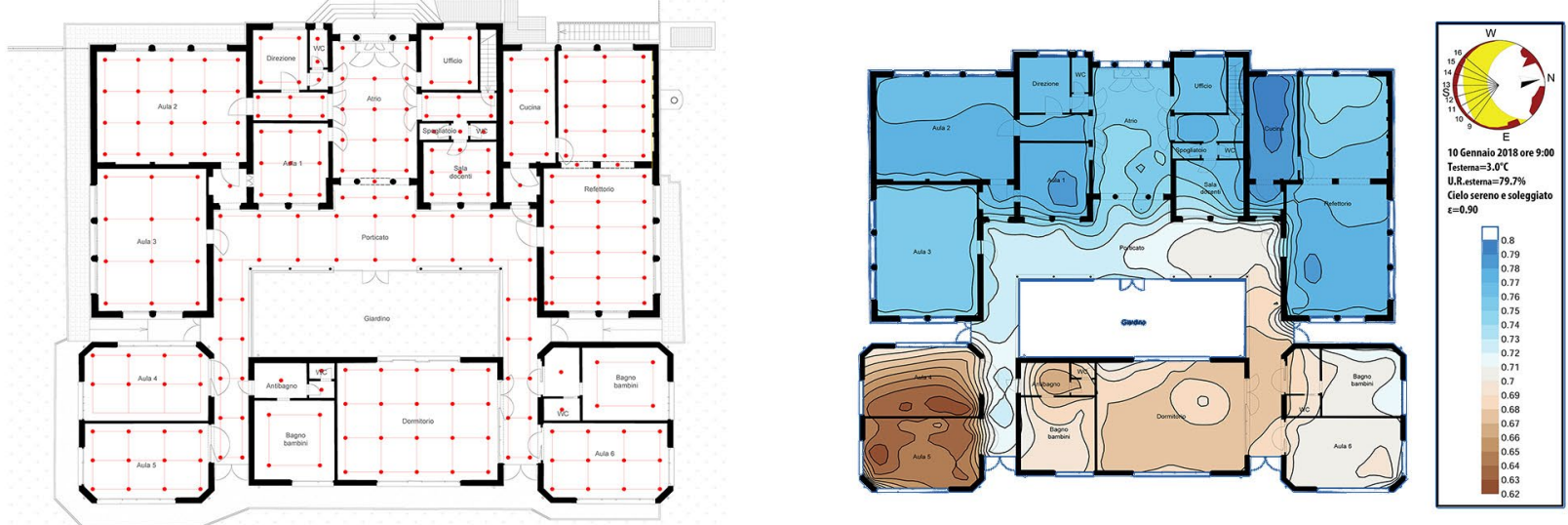

Figure 8. The mapping of the diagnostic analyses on the surface: thermo-hygrometric monitoring of the premises. 

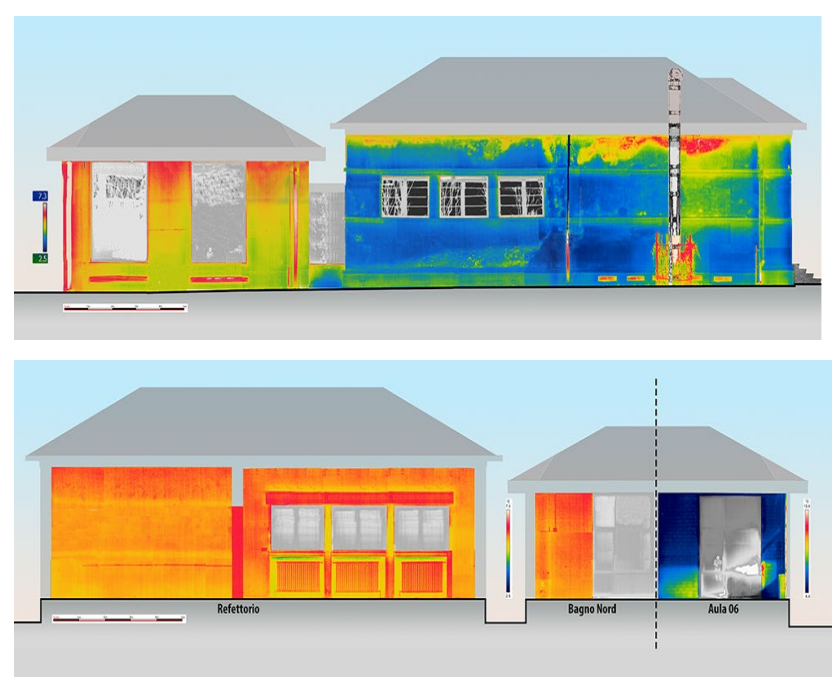

Figure 9. The identification of decay phenomena.

testimony of the process of evolution of human life should take place by applying the same conservation principles already adopted for historical heritage in order to preserve their identity. To this end, the knowledge of the built based on analyticaldocumentary and morphological-type approaches, seen as a starting point for the evaluation and critical representation of the constructed space and imperative base for every coherent adaptive reuse proposal, is mandatory.

3D laser scanning survey ensures high levels of accuracy for the tolerances required in the practice of building restoration and retrofitting. However, the only survey with active sensors is not sufficient but needs to be integrated with modern digital photogrammetry.

The present work highlights the opportunities ensured by each of the techniques that have been employed, all characterised by the common feature of non-invasiveness.

The produced graphic reports were the result of the synergy of the different investigations, all of them indispensable to the purpose envisaged. Unlike traditional surveys, the amount of data acquired is very high. It is, therefore, necessary to operate correctly in order to optimize time and limit costs. A survey of a building so operated is a document of the condition of the construction, an act of memory that shows the building at a given historical moment.

\section{ACKNOWLEDGEMENTS}

The present work is a synthesis of the Master degree thesis of Ing. Pietro Azzola carried out in the framework of an educational internship carried out at the Municipality of Dalmine. The activities have undertaken in collaboration with Architect Corrado Negrini, Councillor for Public Works, Urban Planning and Construction of the City of Dalmine; the Land Planning and Control Services for Land Use and Transformation Operations, directed by Arch. Mauro De Simone and as well as the staff of the archives consulted, in particular, Dr Stefano Capelli of the Dalmine Foundation.

\section{REFERENCES}

Bellini, A., Torsello, P B., 2005, Che cos'è il restauro? Nove studiosi a confronto. Marsilio Editore, Venezia.

Bianchi, G., Bruno, N., Dall'Asta, E., Forlani, G., Re, C., Roncella, R., Santise, M., Vernizzi, C., Zerbi, A., 2016, integrated survey for architectural restoration: a methodological comparison of two case studies, Remote Sensing and Spatial Information Sciences, Volume XLI-B5.

Bison, P., Bortolin, A., Cadelano, G., Ferrarini, G., Furlan, K., \& Grinzato, E., 2012. Geometrical correction and photogrammetric approach in thermographic inspection of buildings. In 11th International Conference on Quantitative InfraRed Thermography.

Campanella, C., 2017, Il rilievo degli edifici: metodologie e tecniche per il progetto, di intervento. Dario Flaccovio Editore, Palermo.

Cardaci, A., Versaci, A., 2018, Rilievo e restauro: un binomio imprescindibile. Approcci metodologici e applicazioni operative finalizzate alla conoscenza e alla conservazione del patrimonio culturale. Aracne Editrice, Roma.

Cardaci, A., Versaci, A., Azzola, P., 2018, Dalla conoscenza al riuso consapevole: il caso studio dell'ex-asilo San Filippo Neri a Dalmine. In ReUSO2018: L'intreccio dei saperi per rispettare il passato interpretare il presente salvaguardare il futuro. Roma, Gangemi. pp.231-242.

Costanzo, A.; Minasi, M.; Casula, G.; Musacchio, M.; Buongiorno, M.F. Combined Use of Terrestrial Laser Scanning and IR Thermography Applied to a Historical Building. Sensors $2015,15,194-213$

Dezzi Bardeschi, M., 1990, Dal disegno per il Restauro al rilievo per la conservazione, In Ricerche sulle architetture lombarde dimenticate: catalogo della mostra. Edizioni Alinea, Firenze.

Lussana., C., 2003, Dalmine dall'impresa alla città: committenza industriale e architettura. Fondazione Dalmine: Bergamo.

Pepe, M., Ackermann, S., Fregonese, L., Achille, C., 2016. 3D Point cloud model color adjustment by combining terrestrial laser scanner and close range photogrammetry datasets. In ICDH 2016: 18th International Conference on Digital Heritage (Vol. 10, pp. 1942-1948). International Journal of Computer and Information Engineering.

Rocha, E. A., Macedo, J. V. S., Correia, P., Monteiro, E. C. B., 2018, Adaptation of a damage map to historical buildings with pathological problems: Case study at the Church of Carmo in Olinda, Pernambuco. Revista de la Asociación Latinoamericana de Control de Calidad, Patología y Recuperación de la Construcción, 8(1), 51-63.

Rosina, E., 2009, Le analisi microclimatiche e sul regime termoigrometrico delle murature. In Il Canopoleno di Sassari da casa professa a pinacoteca. Storia e Restauri. Silvana Editore, Milano.

Sciurpi, F., Carletti, C., Pierangioli, L., 2018. Assessment of thermo-hygrometric indicators for preventive conservation inside museums: in field monitoring and passive microclimatic control strategies applied to "La Specola" museum of Florence. In IOP Conference Series: Materials Science and Engineering (Vol. 364, No. 1, p. 012023). IOP Publishing. 